\title{
The Social Construction of the Commercial Sex Workers in Makassar City
}

\author{
Ridwan, T.R
}

Andi Lolo

Arlin Adam

\section{Universitas Negeri Makassar, Jln. Bonto Langkasa Kampus Gunung Sari Baru, Indonesia} ridwankopertis@yahoo.com,direks2003@yahoo.com,arlin_adam@yahoo.com

\author{
Doi:10.5901/mjss.2016.v7n3s1p215
}

Abstract

This study aims at determining why society tolerates the existence of commercial sex workers. This study used a qualitative method with a phenomenological approach. Researchers in the phenomenological view attempted to understand the meaning of events and its linkages to ordinary people in certain situations. This research was focused on people who often interacted with commercial sex workers who work individually. The locations of this research were on Veteran Street, Sungai Saddang Street, Nusantara Street, and Topaz Street as the segregation places. These streets are very disturbing the surrounding society. The results show that apathy and moral decadence of the society are the factors why people give space of tolerance for the existence of commercial sex workers.

Keywords: Social construction, Apathy, and Moral Decadence.

\section{Introduction}

The phenomenon of women as commercial sex workers in Indonesia is not something new in the society. They are an integral part of our social life. Whether their existence is accepted or not is a matter that deserves to be noticed because their activities exist in the midst of society itself. Various news provided by the media indicates that they exist in almost all regions in Indonesia.

Makassar city as the capital of South Sulawesi province has shown a relatively rapid growth that, of course, has an influence either positive or negative influence. The logical consequence of the development of these circumstances creates various kinds and forms of social issues that have been categorized as issues of social pathology, namely prostitution.

As a social phenomenon, prostitution is a problem that is unremitting discussed by people, and it becomes a burden of the society to solve this problem. It seems that various moral messages and the threat of disease cannot dissociate people from the world of prostitution. The problem of prostitution will always exist everywhere either in a big or small city because they grow and evolve with the times.

The sociological reality in society proves that efforts to eliminate prostitution always discriminate the women. There is a stereotype that women are the primary cause of such actions, although there have been many studies that have revealed who is benefited from the practice of prostitution. Thus, solving the normative issues in which the reality always exists should not be conducted with rigid rules. It can be performed by solving the problem that become the background of this behavior.

Prostitution has always been a social problem or the object of legal affairs and norms. However, these activities proved very hard to be removed. It is all related to the demands of life namely the general economic factor. This factor is the main reason someone would do anything such as being commercial sex workers. Moreover, it is fornication from the perspective of society, religion, and positive law in this country.

The formulation of this research is why society tolerates the existence of commercial sex workers. Therefore, this research aims at determining why society tolerates the presence of commercial sex workers.

Of public concern against commercial sex workers currently require special attention including researchers, researchers get quite upset to photographing and see in depth profession commercial sex workers in the city of Makassar in perspective the theory construction social so that we understand the process construction happening in the society and why is it continue. 


\section{Review of Related Literature}

\subsection{The Perspective of Social Construction by Berger and Luckmann}

The process of interpreting undertaken by each on the environment and aspects beyond itself consists of externalization, internalization, and objectivities. Externalization is the adjustment to the socio-cultural world as a human product. Internalization is that individuals identify themselves to the social institutions in which the individual is a member. Objectivities is social interaction in the intersubjective world that is institutionalized or is undergoing a process of institutionalization.

The term of the social construction of reality is defined as a social process through action and interaction in which individuals are always creating a reality that is owned and subjectively experienced together (Poloma, 2004, p. 301). The origin of the social construction of the constructivist philosophy starts from cognitive constructivist ideas. According to Von Glasersfeld, the definition of cognitive constructivist appears in Mark Baldwin's writings that are widely deepened and propagated by Jean Piaget. Therefore, there are three kinds of Constructivism namely radical constructivism, realism hypothesis, and ordinary constructivism.

a) Radical constructivism can only acknowledge what is formed by our thoughts. The form does not necessarily real-world representation. The radical constructivism ignores the relationship between knowledge and reality as a criterion of truth. The knowledge does not reflect the reality of ontologism. However, a reality is formed by person experiences. Knowledge is always the construction of individuals that cannot be transferred to another individual who passively because the construction should be performed individually. Meanwhile, the environment is a place where construction occurs.

b) In realism hypothesis, knowledge is a hypothesis of the structure of reality that is close to the reality and leads to essential knowledge.

c) Ordinary constructivism takes all the consequences of constructivism and understands knowledge as a description of reality. In this kind of constructivism, personal knowledge is viewed as a description that is formed by the reality of the individual (Suparno, 1997, p. 25).

d) Based on these kinds of constructivism, there is a similarity in which constructivism is viewed as individual analytical work to interpret the world of reality that exists because there is a social relation between the individual and the environment or people around him. The individuals then build own knowledge of reality based on the structure of pre-existing knowledge. It is called social construction by Berger and Luckmann.

\subsection{Understanding the Dialectic advanced by Berger: Externalization, Objectivation, and Internalization}

Social construction theory proposed by Berger and Luckmann is tried to have a synthesis of social phenomena implied in the three moments. They show a social construction of reality regarding its origin that is the result of human creation, synthetic of intersubjective interaction.

Society can be objective reality and subjective reality. As an objective reality, society seems to be outside the human being. Meanwhile, as subjective reality, the individual in the community is an integral part. In other words, individual forms the society, and society forms the individual. The social reality is a double reality. The objective reality is the reality that exists outside the human being while the subjective reality is the fact that exists in the human being.

Through the touch of Hegel, namely thesis, antithesis, and synthesis, Berger found the concept of connecting the subjective and the objective reality through the concept of dialectics. It is known as externalization, objectivities, and internalization. Externalization is the adjustment to the socio-cultural world as a human product. Objectivities is social interaction in the intersubjective world that is institutionalized. Internalization is an individual identifying himself in the middle of the social institutions in which the individual is a member.

In this life, there is a rule or law that guides the various social institutions. The rule is a product of human being to preserve social order. Therefore, although the rules in the social structure are reining, it allows the possibility of "violations" committed by the individual. Violation of the rule is caused by the externalization process that varies from individual. In other words, there is an inability of individuals to adjust to the rule that is used to maintain the social order. Therefore, the problem of change is in the process of this externalization. Thus, in a society that emphasizes social order, people are trying as hard as possible to adapt to the social roles that have been institutionalized, whereas people who love to "muddle social" will be more distaste for adjusting the roles of social which has been institutionalized.

Society as an objective reality is legitimacy. The function of legitimacy is to make objectivation that is institutionalized to be reasonable objectively. For example, mythology not only has a legitimate function of the behavior 
and actions, but also it becomes reasonable when the mythology is understood and carried out. In order to maintain the universe, social organization is required. Because the actual product of human activity, the universe that is constructed socially will change due to human action. Therefore, social organization is required to maintain it. If the maintenance is built fully, then there is the status quo.

Society also can be a subjective reality and internal reality. In the subjective reality, it is required a socialization that serves to maintain subjective reality and transform it. Socialization always takes place in the concept of particular social structure, not only the content but also the success rate. Thus, analysis of micro social or social psychological phenomena of internalization must always be motivated by an understanding of the macro socio-structural aspects.

The structure of the subjective consciousness of individuals in the sociology of knowledge occupies the same position in explaining social reality. Every individual absorbs the form of interpretation of the limited social reality as a reflection of the objective world. In the process of internalization, individuals vary in the dimension of absorption. Some individuals are more absorbing external aspect than internal aspect. However, there are also some individuals who are more absorbing internal aspect than external aspect. Not all individuals can maintain the stability in the absorption of the objective dimension and the dimension of social reality.

The fact received by an individual from social institutions, according to Berger, requires a way to explain and justify the power that is being held and practiced. Thus, the relationship between the individual and the institution is a dialectic (inter-subjective), which is expressed by three moments. First, society is a human product. Second, society is an objective reality. Third, the human is a social product. This dialectic is mediated by the knowledge that is based on the memory of experience on the one hand and by the roles that represent individuals in institutional arrangements (Waters, 1994, p. 35).

Thus, methodically the users of this method take three levels of self-liberation in the form of subjective elements, the confines of hypotheses, and traditional doctrines. Thus, the truth of reality and knowledge will only be obtained from the experience.

\subsection{Society as Objective and Subjective Reality}

According to Berger and Luckmann (1990, p. 66), society can be objective reality and subjective reality. As an objective reality, society seems to be outside the human being. Meanwhile, as the subjective reality, the individual in the community is an integral part. In other words, individual forms the society, and society forms the individual. The social reality is a double reality. The objective reality is the reality that exists outside the human being while the subjective reality is the fact that exists in the human being.

Society as an objective reality, according to Berger and Luckmann (1990, p. 66-67), occurs through the institutionalization and legitimacy. Institutionalization occurs based on activities undertaken by individuals because they do not have their world, and they have to build their world. It is because humans occupy a unique position that is different from animals. It means that they do not have the world like the animal world that is limited to a specific geographical distribution and is closed.

Berger and Luckmann (1990, p. 67-73) reveal that the relationship between humans and their environment is characterized by the openness of the world. Therefore, it allows humans to perform various activities. This relationship makes them develop themselves not based on instinct. However, they develop themselves through many kinds of activities continuously. Thus, in developing themselves, they do not only relate reciprocity with the certain natural environment but also the social order and specific culture connected through the mediation of influential people (significant others). Human development from childhood to adulthood is determined socially.

The human organism also shows the "elasticity" which is exceptional in dealing with the social environment. Here, the human nature is formed by the anthropological constants (world openness and elasticity of instinct structure) that limit and enable sociocultural formations.

Humans jointly produce a humanized environment with the totality of socio-cultural and psychological formations. All formations are the result of productive human activity. Therefore, Berger and Luckmann claim that it is impossible for humans to evolve as a human being in an unusual condition to produce a humanized environment. Therefore, humans need stability in their lives so that the openness of world for human existence must be transformed into the social fabric in the form of relative closure-world.

Thus, the social order is an individual product taking place continuously as long as its externalization is also regularly taking place. Social order is not biologically given. The natural environment does not provide it. In addition, it is not the nature of nature, and cannot be derived from natural law. The social order exists as a product of human activity (Berger and Luckmann, 1990, p. 74-75). 


\section{Method}

\subsection{The Research Approach}

This study used a qualitative method with a phenomenological approach. Researchers in the phenomenological view attempted to understand the meaning of events and its linkages to ordinary people in certain situations. The reason researchers used the qualitative study because symptoms of is holistic or thorough and cannot be transversely so did not impose his research based on variable research, but a whole social situation researched, covering the aspects of place, agents, and activities are interact in synergy. This study aims at understanding the subjects in their world based on their experience. This understanding will move from the dynamics of the experience to the meaning of experience. The phenomenological study describes the meaning of the subjects' experience of the phenomenon being studied.

\subsection{The Focus and Locations of the Research:}

This research was focused on people who often interacted with commercial sex workers who work individually. The locations of this research were on Veteran Street, Sungai Saddang Street, Nusantara Street, and Topaz Street as the segregation places. According to the researchers, these streets are very disturbing the surrounding society.

\subsection{The Subjects of the research}

Determination of the subjects in this study was conducted by using snowball sampling. Snowball sampling technique is carried out by finding people who can provide data about people and other locations that can be the subject of research according to the needs of researchers.

\subsection{Data Analysis:}

The analysis is the process of data collection to be interpreted. Collecting data means classifying the data into a pattern, theme, or category. In the qualitative research, data analysis should be started early. The data obtained in the field soon are outlined in written form and then analyzed (Nasution, 1996, p. 129).

Qualitative analysis can be conducted simultaneously with the process of data collection, data interpretation, and data presentation. In the analysis of qualitative data, the process of data analysis does not constitute separate and distinct segments with other processes, but it goes together and simultaneous with other processes even at the beginning of the study.

In the analysis of qualitative data, some things can be performed simultaneously, such as collecting data from the field, dividing the data into categories with particular themes, formatting the data into a common description, and changing the description into qualitative text.

The researchers must ensure that the process of qualitative data analysis has been conducted based on the data reduction process and interpretation. Data that have been obtained are reduced into a certain pattern, and then the researchers conveyed a categorization theme (sorting out and unifying theme, which have similarities), and then they do the interpretation of these categories based on the schemes that have been obtained.

\section{Results}

\subsection{Why Society Tolerates the Existence of Commercial Sex Workers}

The alibi that exists in some people who consider that today is an odd time and is fed by currents of modernization. It seems that people are allowed to violate our culture as a civilized nation. It seems that there is decadence in our society so that the omission of the practice of prostitution cannot be avoided.

Ironically, the omission of prostitution also occurs because it is supported by the mutually beneficial relationship between the existence of commercial sex workers and traders around localization. In addition, apathy or indifference citizens also further increase the chances of prostitution.

Similarly, in almost every place where sex workers live in Makassar, it seems that societies do not care anymore on prostitution that occurs around the environment. They even feel pity and give an opportunity to seek sustenance in accordance with the profession as commercial sex workers. 
The reason that they have grown with the environmental conditions that exist in the community itself has formed apathy in society. The service seekers or lady-killers also become the issue in this case. They endlessly empower sex workers.

In addition, the tolerance for commercial sex workers to carry out their profession in seeking sustenance is viewed by some people as a natural thing to meet the needs of their family. However, on the other hand, they also expect the atmosphere in the environment is conducive and no significant interference.

Society has now been poisoned by technological advances that impact on the global nature of moral decadence that is getting worse. Pornography and prostitution are things that are not prohibited to be shown even to be discussed.

\section{Discussion}

The place of prostitution in the city of Makassar lately is like mushrooms in the rainy season. This action that is deviate from the moral ethic is very easily found in several places in the city of Makassar. The low attention and lack social control performed by the society itself makes the free sex activity performed by commercial sex workers and their clients increasingly prevalent and difficult to be stopped. Surprisingly, this action that clearly constitutes irregularities character and shame run smoothly without any obstacles and constraints. In addition, it is escaped from the attention of a number of institutions and religious leaders as well as residents.

It is a fact that cannot be denied under any pretext. Although Makassar has the designation as "Madani" or civil society, this immoral practice is continuing every night in Makassar. It shows a sense of indifference or apathy of the public that is increasingly apparent.

The sympathy of the societies towards the environment has been lost. They feel indifferent to what is happening and where the sex workers operate. The urban communities in particular and the Indonesian people, in general, have been formed from modern life selfish. Therefore, they are busy with their private affairs as well as the fulfillment of their basic needs. These problems cannot be blamed. With the current economic conditions, the safety of themselves and their families are considered as a top priority.

Apathy in society makes people close their eyes to what is happening around them. They then do not know the environment so that they no longer recognize the value that has been existing in the society.

The lack of control by the community will lead to a permissive culture. The values that underlie people's behavior as an order should be maintained to be marginalized or even eroded. People have become very permissive to any form of irregularities that occurred because the limit values have faded.

Cultural roots that uphold the values and religious have been uprooted. There is no more the word of taboos, shame, and sin. Sex is no longer understood as something sacred that is only found in the institution of marriage. Sex becomes cheap goods that can be performed by anyone, anytime and anywhere.

The destruction of values that exist in the society is similar to directing human to civilization that is uncivilized. The loss of a sense of caring, respect, value, conscience, and the lack of views on morality, ethics and culture have misled the society about all forms of irregularities including immoral practices that often occur around the environment.

Prostitution can be defined as a job conducted by someone to perform sexual acts with a reward. It can be categorized as a social problem because the society judges that the commercial sex workers considered as a contemptible job. They are regarded as having violated the norms contained in such society. However, if there is no code of ethics or norms in the society that believes that the job is not permitted (not kosher), the society will not consider it as a social problem. In general, there are many opinions expressed by the societies that increasingly lead to the future. The societies seem indifferent, and they do not even have a problem with what they do. All opinions are legitimate to be expressed by the individual. It depends on whether the activity is considered disturbing peace and order of society itself. It is the same with the opinion of some societies that live in Makassar itself.

The above description can be seen from many angles, but we have to keep looking at what is happening in Makassar positively, and it should make our hearts open to understanding every action performed by the commercial workers is the best thing for them for their future.

The balance in the society is a situation that is coveted by every citizen. In that situation, the societies feel that there will be peace because there is no disagreement about the rules for the values prevailing in the society.

Sometimes, the balance is under strain because no decency or collision norms are prevailing in society, and thus society in sickness reveals that prostitution is one of the society's ills because a slump in education and religion could lead to moral degeneration that are familiar with the term 'moral decadence'. All things that happen in this world are not without cause and effect. For example, with advances in technology, aspects that are sacrificed are lifestyle and civilization that are developed in the society. 
Society indirectly becomes victims of human civilization and technology. For the societies in the east, the Europe becomes the direction of technological development. Therefore, the lifestyle and civilization that exist there also indirectly are replicated by the developing country including Indonesia. Sooner or later, the culture and norms are degraded by the western culture that is fundamentally different from the east culture.

Moral decadence has become a common phenomenon that plagued humankind today, especially advocating liberation of western civilization that has undergone tremendous moral damages. Ironically western culture that has suffered moral damages were distributed to Muslim countries. Therefore, the local culture of the Muslim community is contaminated with western culture. The local culture eventually experiences shock culture and is closer to the western lifestyle. Indonesia is one of the victims.

Moral decadence occurs especially among teenagers. Meanwhile, in order to solve the problem, it is still protracted with vague concepts. Moral destruction of Muslims can not be separated from the people that attempts to spread deliberately diseases and the moral conception that faltered the Muslims, and then eventually they fall. Therefore, the majority becomes the minority in quality. The worse thing when the authorities are involved, and the roles of theologian and public figures are weakened.

The younger generation now has gripped the phenomenon of free lifestyle. This lifestyle is very far from the values of Islam and the culture of Indonesia. However, because certain circles want to undermine the morale of the nation, then gradually the younger generation finally stuck. In this case, the role of the media is massive both printed media and electronic media.

If we look at the Indonesian television programs with the educational theme, the program does not invite the children to study hard. The films are there to invite them for dating, having fun and doing promiscuity. The impact is felt by the children in Indonesia from urban to rural societies. Consequently, they have moral decadence significantly.

Women were dragged away to the Western civilization with the slogan of freedom and feminism that result in the destruction of their morals. Therefore, they are usually subjected to exploitation under the pretext of freedom of expression. Every inch of a woman's body is used as a commodity. Wearing sexy clothes and doing fornicate are acted as long as it brings material. The nakedness of women is contested and assessed. Surprisingly, with full awareness, women are lined up to ask to be exploited.

In addition, there is a social problem, namely the lack of correspondence between measures, social values, realities and social actions. The first element and principal social problem is the difference between the values and the real conditions of life. It means that there is an imbalance between the assumptions of society about what should happen and what is going on in reality social life.

Manifest social problems are social problems that arise as a result of imbalances in society. Those imbalances occur due to several things. First, the action between the norms and values that exist in society are not appropriate. Second, the societies dislike the deviating actions. In addition, latent social problems are also related matters that are contrary to the values of society, but they are not recognized. In relation to the above social issues, sociology is not intended to create human beings who are wise and always good in their actions. However, it aims at opening the eyes in order to take into account the result of their actions.

The societies believe that imbalances coming from the manifest social problem can be restored and limited or even eliminated. It is different with latent social problems that are difficult to overcome because although the societies dislike the problem, they are powerless to resolve it. The prevention of prostitution must be performed immediately. If there is no prevention, this social illness and symptoms over time are viewed by society as natural and normal problem. With the presence of this view, it means that they begin to saturate in confronting all the issues associated with prostitution.

If the societies have saturated, the prevention efforts of prostitution will encounter many obstacles. However, the consequences of prostitution are very dangerous and disturbing the public and the generations of children in the future.

\section{Conclusion}

The apathy and moral decadence of the society become the main factors why people give space of tolerance for the existence of commercial sex workers. Therefore, it is suggested that governments and societies can play an active role in finding a right solution for the presence of commercial sex workers. The government's role is expected to be more aggressive in conducting programs that are preventive, rehabilitative, and persuasive in addressing the problem of commercial sex workers. The societies are expected to develop tolerance for the existence of commercial sex workers to understand the positive side. 


\section{References}

Bachtiar, Reno. (2007). Business of Prostitution. Yogyakarta: PINUS

Berger, Peter L. (1969). The Sacred Canopy: Elements of Sociological Theory of Religion. Garden City, New York: Doubleday Company Inc.

Berger, Peter L., J.B. Sudarmanto. (1991). Hearsay from heaven: the theological Meanings in Modern society. Jakarta: LP3ES.

Berger P.L., \&Luckmann T. (1990). The Social Interpretation of the Fact. A treatise on sociology of Knowledge. (Translated by Hasan Basari). LP3ES. Jakarta.

Berghe, Van Den, Pierre. (1967). Dialectic and Functionalism: Toward a Synthesis, in N.J.Human Sexuality. The Journal of Sex Research, Vol.35(1), pp. 10-1.

Kartini, Kartono. (2001). Pathology of Social. Jakarta: Rajawali Press.

Moleong, Lexy. (2007). Qualitative Research Method. Bandung: Rosda Karya

Ritzer, George., \& Goodman J, Douglas. (2008). Theory of Modern Sociology. (6 $6^{\text {th }}$ Ed). Jakarta : Kencana Prenada Media Grup,.

Suryakusuma Julia. (1991). the Social Construction of Sexuality. An Introduction to the Theoretical. Prisma No.7, Juli. 